\title{
A sexualidade feminina na consulta de enfermagem: potencialidades e limites
}

Women sexuality in nursing appointments: potencialities and limits

La sexualidad femenina en la consulta de enfermería: potenciales y limites

\section{Munyra Rocha Silva AssunçãoI, Isabel Helena Pereira Dias' ${ }^{I I}$, Andréia Cristina Barbosa Costa $^{\mathrm{III}}$, Mônica Lá-Sallete Costa Godinho ${ }^{\mathrm{IV}}$, Patrícia Scotini Freitas ${ }^{\mathrm{V}}$, Christianne Alves Pereira Calheiros ${ }^{\mathrm{VI}}$}

\begin{abstract}
Resumo: Objetivo: identificar as potencialidades, limites e necessidades relacionadas à sexualidade de mulheres durante a consulta de enfermagem. Método: estudo descritivo e exploratório, de abordagem qualitativa, realizado com 14 enfermeiras atuantes em Estratégias de Saúde da Família, de um município do Sul de Minas Gerais. Resultados: a assiduidade nas consultas de enfermagem, o vínculo estabelecido e a experiência profissional foram considerados potencialidades; os limites foram: a primeira abordagem do assunto, a existência de tabus e questões culturais e as funções burocráticas do enfermeiro. Perceberam-se, como necessidades, uma maior capacitação profissional, a orientação da população e a implementação de políticas públicas, programas e protocolos. Conclusão: para promover a saúde da mulher é necessário um olhar mais atento e seguro do enfermeiro, pois a sexualidade deve ser vista como parte indissociável da vida feminina.
\end{abstract}

Descritores: Sexualidade; Enfermagem; Saúde da mulher; Estratégia de saúde da família; Consulta de enfermagem

Abstract: Objectives: to identify the potentialities, limits and necessities related to women sexuality during nursing appointments. Method: it is a quantitative and descriptive study from a qualitative view, performed with 14 nurses actives in Family Health Strategies, from a town in the south of Minas Gerais. Results: the attendance in nursing appointments, the established bond and professional experience were considerated potencialities; the limits were: the first approach to the subject, the existence of taboos and cultural aspects and the burocratic roles of the nurse. It is noticed, as necessities, a greater professional training, population

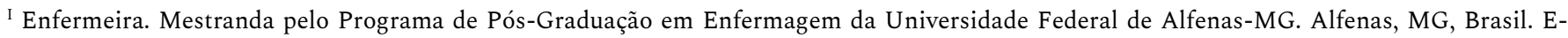
mail: munyrarsilva@hotmail.com ORCID: https://orcid.org/0000-0002-0998-3125

II Enfermeira. Graduação pela Universidade Federal de Alfenas-MG. Alfenas, MG, Brasil. E-mail: isabelhpdias@hotmail.com ORCID: https://orcid.org/0000-0002-6271-0273

III Enfermeira. Doutora. Professora Adjunta da Escola de Enfermagem da Universidade Federal de Alfenas-MG. Alfenas, MG, Brasil. E-mail: andreia.barbosa@unifal-mg.edu.br ORCID: https://orcid.org/0000-0003-3484-9638

IV Enfermeira. Doutoranda pela EERP-USP. Professora Adjunta da Escola de Enfermagem da Universidade Federal de Alfenas-MG. Alfenas, MG, Brasil. E-mail: monica.godinho@unifal-mg.edu.br ORCID: https://orcid.org/0000-0001-7724-6947

${ }^{v}$ Enfermeira. Doutora. Professora Adjunta da Escola de Enfermagem da Universidade Federal de Alfenas-MG. Alfenas, MG, Brasil. E-mail: patricia.freitas@unifal-mg.edu.br ORCID: https://orcid.org/0000-0002-8270-8955

${ }^{V I}$ Enfermeira. Doutora. Professora Adjunta da Escola de Enfermagem da Universidade Federal de Alfenas-MG. Alfenas, MG, Brasil. E-mail: christianne.calheiros@unifal-mg.edu.br ORCID: https://orcid.org/0000-0002-7469-6034
} 
orientation and the implementation of public policies, programs and protocols. Conclusion: in order to promote women health it is necessary a more mindful and safer look of the nurse, whereas sexuality should be seen as an inseparable part of women life.

Descriptors: Sexuality; Nursing; Women’s health; Family health strategy; Nursing Appointments

Resumen: Objetivo: identificar los potenciales, límites y necesidades relacionadas a la sexualidad de mujeres durante la consulta de enfermería. Método: estudio descriptivo y exploratorio, con enfoque cualitativo, realizado con 14 enfermeras que trabajan en Estrategias de Salud Familiar, en un municipio del Sur de Minas Gerais. Resultados: la asistencia en consultas de enfermería, el vínculo establecido y la experiencia profesional se consideraron potenciales; los límites fueron: El primer acercamiento al asunto, la existencia de tabúes y cuestiones culturales y las funciones burocráticas del enfermero(a). Se percibió como necesidades, una mayor capacitación profesional, orientación a la población y la implementación de políticas, programas y protocolos. Conclusión: para promover la salud de las mujeres, es necesario que el enfermero(a) sea muy meticuloso, ya que la sexualidad debe verse como una parte inseparable de la vida femenina.

Descriptores: Sexualidad; Enfermería; Salud de la mujer; Estrategia de salud familiar; Consulta de enfermería

\section{Introdução}

A sexualidade humana é um processo contínuo que abrange aspectos biológicos, psíquicos, sociais, culturais e históricos, configurando-se uma dimensão complexa na vida do ser humano, não se restringindo à meta reprodutiva, mas também constituída pelas relações amorosas e pelo laço afetivo entre as pessoas, podendo interferir diretamente na autoestima, na imagem corporal, nos relacionamentos interpessoais e na saúde física em geral. Nas primeiras décadas do século XX, a saúde da mulher foi incorporada às políticas nacionais de saúde, os programas implementados ainda eram voltados para a assistência à gestação e ao parto. Dessa forma, o Ministério da Saúde lançou o Programa de Assistência Integral à Saúde da Mulher (PAISM), o que constitui em marco histórico, pois introduziu um novo enfoque nas políticas públicas de saúde, propondo uma abordagem global da saúde da mulher em todas as fases do seu ciclo vital. ${ }^{1-3}$

É notório que a sexualidade e a saúde reprodutiva são questões centrais nas políticas brasileiras, percebe-se que a situação relativa aos direitos reprodutivos e sexuais ainda não progrediu o suficiente, configurando-se como aspectos importantes numa abordagem integral à 
saúde da mulher. ${ }^{4}$ Assim, a consulta de enfermagem é crucial, visto que a comunicação instituída propiciará o estabelecimento de vínculo e confiança, além de proporcionar ao usuário uma assistência que produza saúde, autonomia e corresponsabilização na promoção da saúde e melhor qualidade de vida..$^{5-6}$

Mediante a tantos avanços e acesso às informações, a sexualidade da mulher ainda permanece suprimida, e os profissionais de enfermagem enfrentam barreiras, como tabus, preconceitos e dificuldade em abordar o tema. Entende-se que este profissional tem papel fundamental para que estas mulheres desagreguem os medos e os tabus existentes sobre a sexualidade. Ademais, a enfermagem deve se estabelecer enquanto profissão do cuidado, que desenvolve ações complexas, pautadas em uma prática de inclusão, integralidade e eficiência..$^{7-9}$

Nesse contexto, este estudo justifica-se no sentido de contribuição na construção do conhecimento científico na abordagem da sexualidade feminina nas consultas de enfermagem, tendo como questão de pesquisa: Quais as potencialidades, limites e necessidades relacionadas à sexualidade de mulheres durante a consulta de enfermagem? Isto posto, este estudo tem como objetivo identificar as potencialidades, limites e necessidades relacionadas à sexualidade de mulheres durante a consulta de enfermagem.

\section{Método}

Trata-se de um estudo descritivo e exploratório, de abordagem qualitativa. Realizado em 14 unidades de Estratégia de Saúde da Família (ESF) com a participação de 14 enfermeiras que efetivavam a consulta de enfermagem, com experiência mínima de seis meses, devido à criação e vínculo com a população.

A aproximação com as enfermeiras, em um primeiro momento, ocorreu por meio do agendamento da entrevista via telefone. A partir da aceitação das enfermeiras em participar da pesquisa, foi solicitada a assinatura do Termo de Consentimento Livre e Esclarecido, iniciando- 
A sexualidade feminina na consulta de enfermagem: potencialidades e limites $\mid 4$

se em seguida a entrevista semiestruturada na ESF, quando se estabeleceu uma relação interpessoal. Para resguardar a identidade das mesmas, utilizou-se a abreviatura de enfermeira e codinome de cores, escolhidos pelas entrevistadas.

A coleta de dados ocorreu de novembro de 2016 a janeiro de 2017, por meio de entrevistas, com duração média de 30 minutos, realizada no período vespertino, em sala reservada nas ESF, sendo utilizado um instrumento que continha os dados de caracterização das enfermeiras e duas questões norteadoras: "Quais as facilidades e dificuldades para desenvolver uma assistência qualificada à mulher quanto à sexualidade na consulta de Enfermagem?" e "O que você acha importante para melhorar a consulta de enfermagem quanto à sexualidade da mulher?”. O instrumento de caracterização da população abordou as seguintes variáveis sociodemográficas: data de nascimento, sexo, situação conjugal, religião, tempo de atuação na unidade, regime de trabalho e especialização.

As entrevistas foram gravadas em aparelho celular Samsung Galaxy S5 new edition e o processo de análise do estudo se iniciou com a transcrição fidedigna das mesmas, sendo posteriormente organizadas em categorias e codificadas por cores. O depoimento de cada participante foi identificado pelas iniciais Enf. (Enfermeira), seguido por cor, para garantia do anonimato.

Os dados foram analisados pelo método de análise de conteúdo. ${ }^{10}$ Para análise dos dados oriundos das perguntas norteadoras, utilizou-se os seguintes passos: pré-análise, a exploração das entrevistas, das quais emergiram as categorias temáticas e a análise dos resultados. Obtiveram-se as categorias temáticas: "Facilidades encontradas na consulta de enfermagem quanto à sexualidade da mulher”; "Dificuldades encontradas na consulta de enfermagem quanto à sexualidade da mulher"; e "Necessidades para melhorar a consulta de enfermagem quanto à sexualidade da mulher”, que foram posteriormente discutidas entre si e com a literatura.

O estudo atendeu os aspectos éticos da Resolução 466/2012, do Conselho Nacional de Saúde e, o projeto foi aprovado por Comitê de Ética em Pesquisa da Universidade Federal de 
5 | Assunção MRS, Dias IHP, Costa ACB, Godinho MLC, Freitas PS, Calheiros CAP

Alfenas (Unifal-MG), em 13 de outubro de 2016, sob parecer número 1.775.386, CAAE: 60755216.2.0000.5142 e autorizado pela Secretária Municipal de Saúde, foi realizada a pesquisa com a assinatura do termo de autorização Institucional.

\section{Resultados}

Foram entrevistadas 14 enfermeiras das unidades de ESF do município investigado. Quanto à faixa etária, seis participantes se encontravam entre 30 e 39 anos, três entre 40 e 49 anos e cinco entre 50 e 59 anos. Quanto ao estado civil quatro eram solteiras, seis eram casadas ou viviam com companheiro e quatro eram separadas ou divorciadas. Em relação à religiosidade, nove eram católicas e cinco evangélicas.

Em relação ao tempo de atuação, das 14 enfermeiras entrevistadas, seis atuavam há menos de 10 anos na ESF do município e sete afirmavam estar de seis a 11 anos nesta área de trabalho. Todas trabalhavam em regime de 40 horas semanais e uma possuía mais de um vínculo empregatício. Todas possuíam especialização em alguma área, sendo que sete delas em Saúde da Família.

Com o intuito de identificar as potencialidades e os limites para trabalhar a consulta de enfermagem qualificada, quanto à sexualidade e às necessidades para melhorá-las nas ESF de um município do Sul do Estado de Minas Gerais, foram estabelecidas as seguintes categorias temáticas:

\section{Facilidades encontradas na consulta de enfermagem quanto à sexualidade da mulher}

A abordagem da sexualidade feminina durante as consultas de enfermagem nas ESFs foi percebida como uma potencialidade, especialmente no momento da realização do exame preventivo para câncer de colo de útero. É oportuno assinalar que a faixa etária e a PCCU (Prevenção do Câncer de Colo Uterino) interferem positivamente e diretamente na consulta à mulher, como pode ser visualizado nos trechos: 
A sexualidade feminina na consulta de enfermagem: potencialidades e limites $\mid 6$

Eu tenho mais facilidade de abordar a sexualidade com as mulheres adultas, por volta de 40, 50 anos, porque elas têm necessidade de falar como está a vida sexual e como eu tenho um método de colher preventivo bem aberto, deixo elas falarem à vontade, assim consigo manter o intercâmbio e o diálogo. (Enf. Verde)

A maior facilidade que eu aproveito é conversar na hora do preventivo, é o momento que a gente tem [...]. (Enf. Azul)

Evidenciou-se a construção do vínculo com as usuárias por meio da comunicação e escuta ativa, do tempo destinado às mulheres e do convívio. As enfermeiras abordaram que entendem que a liberdade e abertura que elas têm para conversar sobre a sexualidade estabelece esta proximidade, também mais confiança devido aos atendimentos anteriores, que tem com a população:

O que elas não têm de liberdade em conversar com as mães e com as amigas e os médicos, elas vêm e falam comigo. Estou aberta para a fala delas, já é o início desse vínculo [...]. (Enf. Vermelho)

Ela sentiu confiança em mim porque já teve outro atendimento comigo, pessoas que têm uma vida sexual há mais tempo e a iniciaram muito cedo, veem com naturalidade, falam abertamente. (Enf. Pink)

Eu sou bem comunicativa, acho que eu dou liberdade mesmo! Como a gente tem um bom tempo de boa convivência com a população elas já falam o que sentem [...]. (Enf. Marrom)

A experiência profissional e a forma como ela é utilizada no atendimento às mulheres em relação à sexualidade é fundamental para transmitir segurança e profissionalismo durante a consulta de enfermagem, inclusive, faz parte de uma assistência holística às mulheres. A preocupação sobre o que as mulheres pensam da experiência profissional foi apontada pelas enfermeiras com relação à necessidade de demonstrar uma bagagem de conhecimento e o quanto a prática auxilia na assistência com o decorrer do tempo, conforme se verifica: 
A experiência e a idade da gente. Tem coisa que a gente não aprende na faculdade, aprende é na prática do dia a dia com as pessoas que você aborda e a própria vida, a carga de experiência ajuda bastante [...]. (Enf. Pink)

O enfermeiro precisa de experiência, quando se começa a trabalhar, no início, a gente depara com o medo, a insegurança, mas a gente vai aprendendo e vai ficando cada vez melhor, passando segurança para a paciente. (Enf. Marrom)

\section{Dificuldades encontradas na consulta de enfermagem quanto à sexualidade da mulher}

As dificuldades relacionadas à sexualidade das mulheres durante a consulta de enfermagem foram evidenciadas na abordagem do assunto com as mesmas logo no primeiro contato, ou seja, na primeira consulta, nas diferentes etapas do ciclo vital das mulheres, bem como com as casadas ou as muito jovens:

Vejo como dificuldade, quando é a primeira consulta com a profissional. Elas podem até ter alguma dificuldade, algum questionamento e não o fazem, preferem falar que está tudo certo. Eu acho que por ser a primeira vez que estão indo, ou por serem de outra religião, não se sentem à vontade para abordar esse tipo de questionamento. (Enf. Pink)

Uma das coisas que me preocupa muito, principalmente com as mulheres casadas, é se negarem a ter relação com seus parceiros, e eu não sei como lidar com essa situação. Eu oriento a procurar um ginecologista ou o psicológico. Quando eu atendo alguma jovem menor de idade, que vem sozinha, então eu fico preocupada, com medo, sobre o que informar, o que eu posso falar, até onde posso ir. (Enf. Marrom)

Outro ponto identificado como dificuldade, diz respeito aos tabus, questões culturais e falta de abordagem sobre o assunto nas escolas e em ambiente familiar.

Verifico que a questão cultural pode impor dificuldades, pois muitas vezes a mulher entende que tem que ter relação sexual só para satisfazer o outro e não pensa no seu próprio desejo. A sexualidade para a mulher é complicada, porque é tabu, ela tem vergonha do corpo e ela tem medo! Existe essa submissão do sexo, se o parceiro quer, a mulher não quer, mas ela tem que ceder [...] fala-se de 
A sexualidade feminina na consulta de enfermagem: potencialidades e limites $\mid 8$

sexualidade na escola, mas ainda existem restrições, a família tinha que conversar um pouco mais, desde a fase em que começam os porquês [...]. (Enf. Vermelho)

Porque muitas mulheres são criadas de uma forma que tudo é pecado, é proibido, não pode e já o homem tudo pode [...]. (Enf. Verde)

E ainda se identifica as dificuldades devido à grande demanda e aos aspectos burocráticos do papel do enfermeiro.

É difícil trabalhar esse tema, pois é uma população muito grande, são quase 10.000 pessoas na área. Na atenção primária, é um assunto que deveria ser abordado com mais tempo [...] ter muito mais tempo com a paciente para falar sobre isso. (Enf. Vermelho)

É uma luta diária, tanta coisa que vem, tanto sistema para alimentar, que às vezes a assistência mesmo fica a desejar. (Enf. Branco off)

\section{Necessidades para melhorar a consulta de enfermagem quanto à sexualidade da mulher}

Observa-se a necessidade de capacitação profissional sobre a sexualidade, e esta por faixa etária e de forma multifatorial para assistência integral à saúde da mulher, bem como a importância de instrumentos para nortear o atendimento:

Eu acho que tinha que ter uma capacitação melhor sobre o assunto, para poder orientar melhor as pacientes. Saber quais são os pontos que devem ser abordados, falados durante as consultas, sobre as faixas etárias o que priorizar. (Enf. Rosa)

Seria interessante se o município dedicasse um olhar mais atencioso no atendimento a essas pacientes que chegam às consultas. E que os profissionais buscassem uma capacitação para melhorar a abordagem à essas mulheres. (Enf. Roxo)

Eu continuo achando que precisa de capacitação! É necessário planejamento. Se vai trabalhar com instrumentos para nortear o atendimento, para poder abordar, então qual o instrumento seria; ou vamos planejar esse instrumento, porque 
9 | Assunção MRS, Dias IHP, Costa ACB, Godinho MLC, Freitas PS, Calheiros CAP

quando você faz esse atendimento direcionado, você já vem e aborda o assunto, às vezes fica mais fácil [...]. (Enf. Amarelo)

Verifica-se a educação/orientação como estratégia para melhorar a assistência, por meio de palestras, oficinas sobre sexualidade, grupos operativos com adolescentes nas escolas e com mulheres de idades distintas, para estabelecer troca de experiência e maior proximidade com a enfermagem e possibilitar trabalhar a prevenção:

Talvez mais palestras, porque aqui há mais uma abordagem individual, a gente não está tendo tempo desse coletivo sabe, eu acho que às vezes no coletivo, iria ser mais fácil essa abordagem. Eu acho que seria bom uma educação em saúde [...]. (Enf. Branco off)

De repente oficinas de sexualidade, grupos operativos, para se trabalhar com as adolescentes, porque eu falo que hoje a gente trabalha mais a questão da redução de danos, estão tendo uma vida sexual muito cedo, precoce, então, tem que estar mais próxima delas de alguma forma para explicar a importância da redução dos danos futuros na vida dessas jovens. Então, se elas não estão conseguindo aderir as minhas orientações aqui, de repente seria interessante tentar associarem-se a um grupo operativo. Seria troca de experiências entre jovens. Eu acho que isso resolveria esse problema. (Enf. Cinza)

A unidade básica tem que trabalhar a parte preventiva com a mulher, tem que fazer grupo de mulheres, palestras com relação à sexualidade da mulher [...]. (Enf. Branco)

Ter grupos que façam demonstrações e que possam ir até a escola proferir palestras, acho que seria bom. (Enf. Dourado)

Seria interessante trabalhar com um grupo de mulheres a fim de saber quais são suas dúvidas sobre sexualidade, seus tabus, quais são suas dificuldades com seus parceiros, durante o ato sexual, que tivessem a mesma faixa etária, assim, estaríamos lidando com situações variadas. (Enf. Vermelho)

O enfermeiro como agente facilitador, durante a assistência de enfermagem à mulher, exerce uma importante função de fornecer informações com relação à sexualidade, não somente 
no âmbito do ato sexual, mas multifatorial, o qual engloba aspectos espirituais, físicos, sociais e morais. Apesar de ainda haver um déficit de conhecimento acerca das orientações sobre sexualidade humana, este profissional pode atuar como orientador dos variados questionamentos sobre o tema, porém nos registros das entrevistas verifica-se uma forte assistência voltada apenas ao ato sexual:

Eu ofereço os gelzinhos, porque muitas têm um ressecamento vaginal muito grande. Eu procuro orientar o que ela vai fazer, para se estimular, falo das preliminares, do que ela pode fazer para melhorar a relação sexual [...]. (Enf. Azul marinho)

Oriento o uso de lubrificantes, e em último caso, encaminho para o médico, para ele propor reposição hormonal. Basicamente, são essas as orientações. (Enf. Branco off)

Orientar a paciente a buscar novas experiências com seu parceiro, procurando sair da rotina, para melhorar o seu prazer no momento sexual. A rotina acaba desgastando. Depende da queixa a gente continua naquela abordagem [...]. (Enf. Pink)

Por fim, é preciso dar-se conta de que a sexualidade é pouco trabalhada no contexto multifatorial, bem como na atuação profissional para garantir a abordagem integral à saúde da mulher.

Eu acho que deveriam existir mais atividades implantadas para a saúde da mulher, para suprir a necessidade destas, como grupos, oficinas, rodas de conversas que englobem diferentes faixas etárias [...]. (Enf. Branco)

Uma das coisas que eu acho muito importante é mudar o horário da ESF para atender mais mulheres. Talvez uma vez por semana, à noite, até às $20 \mathrm{~h}$ [...]. (Enf. Marrom) 


\section{Discussão}

O enfermeiro possui papel fundamental na consulta de enfermagem e coleta do PCCU, pois o enfoque durante a consulta é não apenas na queixa principal ou nos exames de rotina da mulher. Sendo assim, aproveita-se desse momento para uma escuta qualificada da usuária, transmitindo orientações e informações, criando um vínculo de confiança mútua.

É nesse contexto, que se insere o enfermeiro como gerador de saúde e de bem-estar às mulheres, pois é nessa consulta que ele tem a oportunidade de escutar a mulher, para saber sobre as dificuldades enfrentadas, se ela se sente protegida, confiante e tranquila; faz parte também de sua função, efetuar apoio integral às mesmas que buscam a unidade de saúde, em todos os estágios do ciclo vital, atentando-se para as transformações que estão acontecendo e ainda buscar quebrar regras e tabus conjuntamente, para que ela possa desfrutar de todos os tipos de prazeres e sensações. ${ }^{11-12}$

O vínculo do enfermeiro com a usuária propicia estabelecer uma relação horizontalizada, a partir do acolhimento, da escuta sensível, do diálogo e das orientações, demonstrando interesse pelas queixas e indagações das mesmas, o que contribui para o estabelecimento e fortalecimento do vínculo. Assim, a enfermagem almeja ter nesse momento uma oportunidade de valorização da singularidade de cada usuária, contribuindo para o estabelecimento de responsabilização mútua pelo cuidado produzido e também trazendo uma facilidade para se discutir a temática sobre a sexualidade..$^{13}$

Foi possível inferir, também, que a construção da identidade profissional acontece ao longo da sua atuação. Contudo, demonstrar traços característicos da profissão e possuir experiência, transmitindo segurança, profissionalismo e conhecimento, facilita a abordagem à mulher.

O enfermeiro, no contexto de sua responsabilidade, apresenta comprometimento com o saber e o fazer na sua prática profissional. Neste sentido, precisa entender e valorizar as múltiplas relações que permeiam o processo de comunicação e interação no cuidado e enfrentar 
A sexualidade feminina na consulta de enfermagem: potencialidades e limites $\mid 12$

o desafio de ser um agente transformador, adotando uma prática baseada na comunicação sensível, de modo que se tenha uma relação concreta e firme com as usuárias, contribuindo para a prestação de uma assistência humanizada. ${ }^{14}$

Estudos coadunam com os achados, evidenciando que o tema sexualidade ainda é superficialmente discutido ou não debatido nos diversos estágios do ciclo vital, a influência da cultura na educação da mulher e na conduta da família em relação à sexualidade, influencia na dificuldade em abordar esse assunto durante a consulta. O encaminhamento para outros profissionais é comum frente às demandas relacionadas à sexualidade da mulher, quando essa temática não consegue ser compreendida e resolvida pelo enfermeiro. Destacam também, que em sua prática profissional, não encontram meios para falarem da sexualidade ou da saúde sexual, devido à existência de lacunas na formação, atitudes marcadamente conservadoras pelo desconhecimento sobre o assunto e formas de abordá-lo. ${ }^{15-16}$

As pesquisas apontam que mesmo na atualidade, ao falar sobre sexualidade ainda se depara com tabus decorrentes da educação recebida, da falta de informações ou opinião pessoal. A maioria das mulheres demonstra certa retração diante dos questionamentos relacionados à saúde sexual/relação sexual. Isto se deve ao fato de existir barreiras culturalmente construídas relacionadas à mulher e sua sexualidade, bem como o distanciamento desse tema da assistência de enfermagem na atenção primária. Além disso, a falta de educação sexual nas escolas e na conjuntura familiar, são tidas como uma das causas prováveis do pouco conhecimento acerca da sexualidade. ${ }^{17-18}$

Considera-se que a enfermagem pode colaborar para eliminar alguns mitos relacionados à sexualidade, todavia, estes profissionais muitas vezes não se sentem preparados para lidar com o assunto. Nesse sentido, é válido haver atividades, programas e orientações sobre educação sexual nos vários cenários sociais e educacionais, para que este tema seja discutido de forma natural, perante a sociedade. Dessa forma, a sexualidade feminina poderá ser abordada por 
enfermeiros, não somente no aspecto biológico, mas também em outros aspectos e valores, estabelecendo confiança e vínculo com as usuárias. ${ }^{19-20}$

Para facilitar o manejo da sexualidade durante uma assistência, se faz necessária a utilização de recursos como instrumentos, protocolos, manuais de orientações e programas educacionais. Outra estratégia satisfatória para auxiliar nesse processo, é a educação em saúde e a criação de grupos operativos também nas escolas, com o intuito de promover a educação adequada aos alunos, pais e funcionários sobre a sexualidade e a desconstrução de pré-conceitos sobre a temática. ${ }^{21}$ É importante que a família e a comunidade também desempenham um papel na orientação sexual, com informações relacionadas à sexualidade e os aspectos positivos do sexo. ${ }^{22-23}$

Outra questão diz respeito ao curto intervalo de atendimento às usuárias e outras atividades técnicas e burocráticas que acabam absorvendo muito tempo. Dessa forma, deve-se considerar o planejamento de atividades para a otimização do tempo determinando as ações prioritárias, fazendo o uso, por exemplo, da Sistematização da Assistência de Enfermagem (SAE), de modo que o cuidado de Enfermagem seja adequado, individualizado e efetivo. A demanda da população atendida e a falta de tempo são queixas relevantes e atuam como barreiras, comprometendo, assim, a assistência de enfermagem. ${ }^{12,24}$

Contudo, as enfermeiras buscam proporcionar resolução às demandas e as situações sofridas pelas mulheres. Dessa maneira, cabendo-lhes, a utilização de recursos disponíveis que possam auxiliar a relação sexual, ${ }^{16}$ como exemplo, a prescrição ou indicação do uso de gel lubrificante, permitindo assim, uma maior satisfação na vivência da sexualidade.

Por fim, o estudo evidenciou a necessidade de desenvolvimento de políticas específicas que abordem a sexualidade no município, além da criação de novos programas. Ademais, a adaptação do horário de funcionamento das unidades, com vista a melhoria do acesso também foi salientada, assim como, a educação em saúde sobre a temática. 


\section{Considerações Finais}

A consulta de enfermagem possui relevância na Estratégia de Saúde da Família visto que o enfermeiro é o elemento que compõe a equipe e está capacitado para o atendimento das mulheres da sua área de abrangência, incluindo adolescentes, adultas, gestantes, puérperas, no climatério e idosas, fortalecendo sua autonomia profissional e promovendo o acolhimento que facilita o acesso das mesmas ao serviço, fortalecendo o vínculo e proporcionando uma avaliação mais abrangente e resolutiva.

As enfermeiras participantes do estudo elencaram como potencialidades a realização do exame preventivo, uma vez que este favorece a comunicação entre a usuária e o profissional. Também alegaram que a existência de vínculo entre elas favorecia a abordagem da sexualidade, ao mesmo tempo que abria espaço para uma escuta ativa.

Os limites observados na consulta de enfermagem dizem respeito à abordagem de questões ginecológicas, sociais, psicológicas e especialmente relacionadas à sexualidade já na primeira consulta, ao passo que a dificuldade se intensifica, quando se trata de mulheres casadas ou muito jovens. Outras dificuldades encontradas foram o questionamento dos tabus e das influências religiosas, o tempo de consulta curto, diante de uma demanda do serviço, o excesso de questões burocráticas as quais interferem na assistência integral, além da insegurança e falta de preparo do profissional.

As profissionais entrevistadas sugerem a necessidade de melhoria da qualidade da consulta de enfermagem, a qual pode ser alcançada por meio da capacitação profissional, orientação e educação em saúde, maximização do tempo para organização de grupos operativos na comunidade, especialmente com as mulheres mais jovens e parcerias com escolas/universidades para uma educação abrangente, além de extensão do horário de atendimento nas unidades de saúde. Dessa maneira, oferecer às mulheres, durante a consulta de 
enfermagem, uma atenção integral, qualificada e humanizada, com respeito e ética, abrangendo todas as fases do ciclo vital, colocando-as como elemento central do atendimento.

No entanto, verifica-se que o estudo é limitado pelo número de enfermeiras entrevistadas e especificamente, quando realizado em um único município. Recomenda-se, que novas pesquisas sejam realizadas com um número maior de enfermeiros de municípios e regiões distintas, com culturas e contextos diferentes, com o intuito de obter resultados ampliados, múltiplas visões. Além disso, a escassez de investigações desenvolvidas no que tange as consultas de enfermagem, especificamente no que se refere à sexualidade da mulher ao mesmo tempo que se apresenta como limitação para discussão dos dados coletados é fato propulsor para o desenvolvimento de novos achados. Conhecer sobre este assunto em diversas regiões com tamanha riqueza cultural e ainda tão distante dos olhos de profissionais de saúde é fundamental para se pensar em uma assistência que seja eficaz a estas pessoas.

\section{Referências}

1. Ministério da Saúde (BR), Secretaria de Atenção à Saúde, Departamento de Atenção Básica. Saúde sexual e saúde reprodutiva [Internet]. 2013 [acesso em 2019 abr 10]; Brasília (DF): Ministério da Saúde; 2013. Disponível em: http://bvsms.saude.gov.br/bvs/publicacoes/saude_sexual_saude_reprodutiva.pdf

2. Mollaioli D, Ciocca G, Limoncin E, Di Sante S, Gravina GL, Carosa E, et al. Lifestyles and sexuality in men and women: the gender perspective in sexual medicine. Reprod Biol Endocrinol [Internet]. 2020 [acesso em 2020 fev 24];18(10):1-11. Disponível em: https://doi.org/10.1186/s12958-019-0557-9

3. Figueiroa MN, Menezes MLN, Monteiro EMLM, Andrade ARL, Fraga DPF, Oliveira MV. Nursing students' perception of training on human sexuality. Referência [Internet]. 2017 [acesso em 2019 nov 5];Série $\quad \operatorname{IV}(15): 21-30 . \quad$ Disponível https://web.esenfc.pt/v02/pa/conteudos/downloadArtigo.php?id_ficheiro=1286\&codigo=

4. Carloto CM, Damião NA. Direitos reprodutivos, aborto e Serviço Social. Serv Soc Soc [Internet]. 2018 [acesso em 2019 ago 16];(132):306-25. Disponível em: http://www.scielo.br/scielo.php?script=sci_arttext\&pid=S0101-66282018000200306\&lng=pt\&tlng=pt

5. Ferreira MLSM, Tank M, Meneguin S, Mazzetto FMC, Paula TC, Israel SC. Percepção das mulheres sobre consulta de enfermagem ginecológica. Rev Uningá [Internet]. 2016 [acesso em 2019 ago 16];50(1):93- 
7. Disponível em: http://revista.uninga.br/index.php/uninga/article/view/1327/945

6. Barbosa MIS, Bosi MLM. Vínculo: um conceito problemático no campo da Saúde Coletiva. Physis [Internet]. 2017 [acesso em 2020 fev 25];27(4):1003-22. Disponível em: http://dx.doi.org/10.1590/S010373312017000400008

7. Alves ERP, Leite GO, Calazans JCC, Costa AM, Santos SR, Dias MD. Scientific production about the sexuality of women in climacteric: an integrative review. Rev Pesqui (Univ Fed Estado Rio J). [Internet]. 2015 [acesso em 2019 ago 16];7(2):2537-49. Disponível em: http://seer.unirio.br/index.php/cuidadofundamental/article/view/3292

8. Almeida MP, Melo MCP, Silva LS, Santos ADB. Atenção em saúde no planejamento reprodutivo: atitudes e práticas de enfermeiros. Rev Enferm UFSM [Internet]. 2016 [acesso em 2019 abr 12]; 6(2):27080. Disponível em: http://dx.doi.org/10.5902/2179769220490

9. Traumer L, Jacobsen MH, Laursen BS. As experiências de sexualidade dos pacientes como um assunto tabu no sistema de saúde dinamarquês: um estudo de entrevista qualitativa. Scand J Caring Sci [Internet]. 2019 [acesso em 2020 fev 25]; 33(1):57-66. Disponível em: https://onlinelibrary.wiley.com/doi/full/10.1111/scs.12600

10. Bardin L. Análise de conteúdo. Lisboa: Edições 70; 2009. 280 p.

11. Catafesta G, Klein DP, Silva EF, Canever BP, Lazzari DD. Consulta de enfermagem ginecológica na estratégia saúde da família. Arq Ciênc Saúde [Internet]. 2015 [acesso em 2019 maio 02];22(1):85-90. Disponível em: https://doi.org/10.17696/2318-3691.22.1.2015.32

12. Aoyama EA, Pimentel AS, Andrade JS, Daniel WV, Souza RAG, Lemos LR. Assistência de Enfermagem na prevenção do câncer de colo de útero. Braz J Health Rev [Internet]. 2019 [acesso em 2019 maio 04];2(1):162-70. Disponível em: http://www.brjd.com.br/index.php/BJHR/article/view/877

13. Santos FPA, Acioli S, Rodrigues VP, Machado JC, Souza MS, Couto TA. Práticas de cuidado da enfermeira na Estratégia Saúde da Família. Rev Bras Enferm [Internet]. 2016 [acesso em 2019 maio 4];69(6):1060-7. Disponível em: https://doi.org/10.1590/0034-7167-2016-0273

14. Broca PV, Ferreira MA. Processo de comunicação na equipe de enfermagem fundamentado no diálogo entre Berlo e King. Esc Anna Nery Rev Enferm [Internet]. 2015 [acesso em 2020 fev 25]; 19(3):46774. Disponível em: http://www.scielo.br/scielo.php?pid=S1414$81452015000300467 \&$ script=sci_abstract\&tlng=pt

15. Macleod C, Nahmo-Murire M. The emancipatory potential of nursing practice in relation to sexuality: a systematic literature review of nursing research 2009-2014. Nurs Inq [Internet]. 2016 [acesso em 2019 maio 07];23(3):253-66. Disponível em: https://onlinelibrary.wiley.com/doi/epdf/10.1111/nin.12131

16. Mann CG, Monteiro S. Sexualidade e prevenção das IST/aids no cuidado em saúde mental: o olhar e a 
prática de profissionais no município do Rio de Janeiro, Brasil. Cad Saúde Pública [Internet]. 2018 [acesso em 2019 nov 10];34(7):e00081217. Disponível em: https://doi.org/10.1590/0102-311x00081217

17. Freire AL, Araújo KS, Vila ACD, Araújo MAS. Assistência de enfermagem à mulher no climatério e sua sexualidade: relato de experiência na atenção básica. Rev Trab Academ Universo Goiânia [Internet]. 2016 [acesso em 2019 maio 10];1(1). Disponível em: http://revista.universo.edu.br/index.php?journal=3GOIANIA4\&page=article\&op=view\&path\%5B\%5D=2366

18. Santos SMP, Freitas JLGS, Freitas MIF. Roteiros de sexualidade construídos por enfermeiros e a interface com a atenção em infecções sexualmente transmissíveis/HIV. Esc Anna Nery Rev Enferm [Internet]. 2019 [acesso em 2019 nov 10];23(4):e20190078. Disponível em: https://doi.org/10.1590/2177-9465ean-2019-0078pt

19. Souza CL, Gomes VS, Silva RL, Silva ES, Alves JP, Santos NR, et al. Aging, sexuality and nursing care: the elderly woman's look. Rev Bras Enferm [Internet]. 2019 [acesso em 2020 fev 25]; 72(Supl 2):71-8. Disponível em: https://doi.org/10.1590/0034-7167-2018-0015

20. Oliveira EL, Rezende JM, Gonçalves JP. História da sexualidade feminina no Brasil: entre tabus, mitos e verdades. Rev Ártemis [Internet]. 2018 [acesso em 2019 maio 05];26(1):303-14. Disponível em: https://doi.org/10.22478/ufpb.1807-8214.2018v26n1.37320

21. Ahari SB, Moghadam ZB, Azin SA, Maasoumi R. Concerns and educational needs of Iranian parents regarding the sexual health of their male adolescents: a qualitative study. Reprod Health [Internet]. 2020 [acesso em 2020 fev 25];17(24):1-9. Disponível em: https://doi.org/10.1186/s12978-020-0883-6

22. Garzón-Orjuela N, Samacá-Samacá D, Moreno-Chaparro J, Ballesteros-Cabrera MDP, EslavaSchmalbach J. Effectiveness of sex education interventions in adolescents: an overview. Compr Child Adolesc Nurs [Internet]. 2020 [acesso em 2020 fev 25];12:1-34. Disponível em: https://www.tandfonline.com/doi/abs/10.1080/24694193.2020.1713251?journalCode=icpn21

23. Grossman JM, Nagar A, Charmaraman L, Richer AM. A larger ecology of family sexuality communication: extended family perspectives on relationships, sexual orientation, and positive aspects of sex. Int J Environ Res Public Health [Internet]. 2020 [acesso em 2020 fev 25];17(3):1057. Disponível em: https://doi.org/10.3390/ijerph17031057

24. Aguilar RP, Soares DA. Barreiras à realização do exame Papanicolau: perspectivas de usuárias e profissionais da Estratégia de Saúde da Família da cidade de Vitória da Conquista-BA. Physis [Internet]. 2015 [acesso em 2019 nov 10];25(2):359-79. Disponível em: https://doi.org/10.1590/S010373312015000200003 


\section{Autor correspondente}

Munyra Rocha Silva Assunção

E-mail: munyrarsilva@hotmail.com

Endreço: Rua João Lopes, 191. Paranazinho

CEP: 37115000

\section{Contribuições de Autoria}

\section{1 - Munyra Rocha Silva Assunção}

Concepção e planejamento do projeto de pesquisa, obtenção ou análise e interpretação dos dados, redação e revisão crítica.

\section{2 - Isabel Helena Pereira Dias}

Concepção e planejamento do projeto de pesquisa, obtenção ou análise e interpretação dos dados, redação e revisão crítica.

\section{3 - Andréia Cristina Barbosa Costa}

Redação e revisão crítica

\section{4 - Mônica Lá-Sallete Costa Godinho}

Redação e revisão crítica

\section{5 - Patrícia Scotini Freitas}

Redação e revisão crítica

\section{6 - Christianne Alves Pereira Calheiros}

Concepção e planejamento do projeto de pesquisa, obtenção ou análise e interpretação dos dados, redação e revisão crítica.

\section{Como citar este artigo}

Assunção MRS, Dias IHP, Costa ACB, Godinho MLC, Freitas PS, Calheiros CAP. A sexualidade feminina na consulta de enfermagem: potencialidades e limites. Rev. Enferm. UFSM. 2020 [Acesso em: Anos Mês Dia]; vol.10 e:68: 1-18. DOI:https://doi.org/10.5902/2179769239397 